\title{
Total Ankle Replacement for Treatment of End-Stage Osteoarthritis in Elderly Patients
}

\author{
Beat Hintermann, Markus Knupp, Lukas Zwicky, and Alexej Barg \\ Clinic of Orthopaedic Surgery, Kantonsspital Liestal, 4410 Liestal, Switzerland \\ Correspondence should be addressed to Alexej Barg, alexejbarg@mail.ru
}

Received 28 February 2012; Accepted 19 April 2012

Academic Editor: Iris Reuter

Copyright () 2012 Beat Hintermann et al. This is an open access article distributed under the Creative Commons Attribution License, which permits unrestricted use, distribution, and reproduction in any medium, provided the original work is properly cited.

\begin{abstract}
End-stage osteoarthritis of the ankle is a disabling problem, particularly in elderly patients who experience an overall loss of mobility and functional impairment and who then need compensatory adaption. Ankle arthrodesis, which has been demonstrated to provide postoperative pain relief and hindfoot stability, leaves the patient with a stiff foot and gait changes. For elderly patient, these changes may be more critical than generally believed. Additionally, the long duration of healing and rehabilitation process needed for ankle arthrodesis may be problematic in the elderly. In contrast to ankle arthrodesis, total ankle replacement has significant advantages including a less strenuous postoperative rehabilitation and preservation of ankle motion which supports physiological gait. Recently, total ankle replacement has evolved as a safe surgical treatment in patients with end-stage ankle osteoarthritis with reliable mid- to long-term results. Total ankle replacement needs less immobilization than arthrodesis and does allow for early weight-bearing and should be considered as a treatment option of first choice in many elderly patients with end-stage osteoarthritis of the ankle, especially in elderly patients with lower expectations and physical demands.
\end{abstract}

\section{Introduction}

The ankle joint has a much lower incidence of symptomatic osteoarthritis (OA) compared to other major joints of the lower extremity [1]. This, despite the facts that the articular cartilage in the ankle experiences the greatest contact force per unit area of any major joint in the body and the ankle joint is one of the most commonly injured areas in orthopaedic surgery [1-3]. However, degenerative OA of the ankle is a constantly growing problem: currently approximately $1 \%$ of the world's adult population is affected by ankle OA leading to significant mental and physical disabilities [4].

Trauma is the primary cause of ankle OA $[5,6]$. Valderrabano et al. reviewed 406 ankles that presented with symptomatic end-stage ankle arthritis and found 78\% secondary to previous trauma [6]. Patients usually presented with a lower leg fracture in the history, but also repetitive ligamentous injuries of the hindfoot complex may lead to degenerative OA of the ankle [7]. Primary arthritis (possibly secondary to misalignment) occurred in up to $10 \%$ of all patients. The remaining $10-15 \%$ of patients developed secondary ankle $\mathrm{OA}$ due to the following underlying diseases: rheumatoid disease, hemochromatosis [8], haemophilia [9], gout [10], clubfoot [11], aseptic talar necrosis, and after joint infection.

Ankle arthrodesis remains an important treatment option in patients with end-stage ankle OA $[12,13]$. After a successful fusion, patients consistently report both, pain relief and improved mobility [12]. However, many clinical studies describe short- and long-term problems following ankle arthrodesis including acute or chronic infection, delayed union, and decreased functional ability $[12,14]$. For the majority of patients who achieve full healing of the arthrodesis, the time of convalescence can be difficult: time duration to achieve complete bone healing may range from 12 to 20 weeks. The postoperative recovery involves some form of immobilization and restricted weight-bearing activities, which can cause significant leg muscle atrophy. Even after the ankle arthrodesis is fully healed, some patients may develop profound dysfunction in the long term. Many authors make note of significant limitations with walking inclines, accommodating uneven ground, driving, 
and athletic activities [14-16]. Formal gait studies after ankle arthrodesis show decreased cadence and stride with decreased motion of the midfoot and hindfoot complexes [17-19]. Gait and function may be also significantly affected if patients develop adjacent joint OA. Coester et al. found in their long-term clinical observational study that majority of patients who underwent an ankle arthrodesis has developed degenerative changes in the ipsilateral foot but not the knee [20]. Similar findings were observed in the long-term study by Fuchs et al., showing deficits in the functional outcome, limitation in the activities of daily living, and radiological changes in the adjacent joints in patients 20 years after ankle arthrodesis [16].

Although ankle arthrodesis is a valid treatment option for end-stage ankle arthritis, its risks and sequelae cannot be ignored. Total ankle replacement (TAR) using current prosthesis designs have evolved to reliable treatment option in patients with end-stage ankle OA. Therefore, ankle fusion is no longer the "gold standard" therapy in this patient cohort [21]. Despite significant progress, concerns still persist related to the feasibility of TAR in patients with bad bone and soft tissue quality, as is often the case in elderly after previous trauma or systemic disease.

The purpose of this paper is therefore to evaluate the potential benefits of TAR in elderly patients with age over 60 years [22], in particular to its advantages with regard to ankle arthrodesis.

\section{Biomechanics and Gait Analysis}

The biomechanics of gait in healthy patients with nonarthritic ankles are clearly different when compared with patients with arthritic, fused, and replaced ankles [19, 21, 23-25].

In choosing between fusion and TAR, benefits in favour of TAR include restoring ankle motion, improving gait biomechanics, and avoiding advanced adjacent joint degeneration more commonly seen following ankle fusion [19, 21, 23-28]. Restoring or at least improving upon gait biomechanics of patients with end-stage ankle arthritis is one of the main goals of surgical treatment for this disease.

Ankle fusion and TAR patients can be expected to have slower gait velocities when compared with healthy control groups but faster speeds when compared with their preoperative arthritic ankle condition $[17,19,23,25]$. TAR patients exhibit a fairly symmetric gait, while ankle fusion patients require significant compensatory mechanisms to obtain a steady, symmetric gait, including increased midfoot joint motion as well as increased range of motion of the ipsilateral knee [17, 19, 23, 25].

In summary, though patients with a fused ankle can be expected to have a reasonably efficient gait, TAR may offer the patient a more normal gait with less negative impact on segmental motion of the whole lower limb and stress concentration on adjacent joints.

\section{Surgical Technique and Postoperative Care}

Meticulous preoperative planning is the main step for success of TAR [29]. Evaluation in the outpatient clinic entails a detailed history taking, including an evaluation of previous infection, trauma, surgeries, failure or success of treatments, location of pain, social circumstances, previous and current activity level, expectations of treatment, tolerance for revision surgery and general health, especially as it relates to a history of neuropathy and/or diabetes. Also, all previous medical reports (e.g., surgery reports) and imaging studies should be completely collected.

The routine physical examination includes careful inspection of the entire foot and ankle. Hindfoot stability should be assessed manually with the patient sitting. Ankle alignment and range of motion are assessed with the patient standing. Range of motion is determined clinically with a goniometer placed along the lateral border of the leg and foot $[30,31]$. Assessment of the subtalar motion and palpation of sinus tarsi may help to exclude subtalar OA. The patients gait is observed clinically and then analyzed using pedobarography in most patients [32]. All affected ankles need to be preoperatively evaluated based on weight-bearing radiographs in three planes. The Saltzman view is used for standardized assessment of varus and valgus deformity of the hindfoot [33]. Single-photon emission-computed tomography (SPECT-CT) can be performed for an accurate assessment and localization of degenerative changes in the adjacent joints [34, 35].

Most manufactures of ankle prostheses provide reliable instrumentation to perform the appropriate bone cuts and to prepare the resection surfaces to accommodate the prosthesis components. Most surgeons use an anterior approach for exposure of the ankle (Figure 1). Careful dissection of soft tissues and avoidance of any unnecessary soft tissue retraction are keys to success to avoid postoperative wound healing complications. Release of any soft tissue contracture is mandatory to gain joint motion, but also to balance the talus properly within the ankle mortise. Heel cord lengthening may be advised in some cases of equines contracture; its use should be very restrictive as patients will often complain about longstanding soft tissue pain along the tendon and loss of plantar flexion power.

Combined peritalar and ankle arthritis, and complex misalignment of the ankle joint complex are complex and challenging clinical entities [36-40]. Combined peritalar and ankle arthritis and varus/valgus preoperative deformity can be successfully treated with TAR in selected cases but need in most instances additional procedures at the same time [39]. Attention to detail, a meticulous preoperative evaluation, and a carefully planned or staged surgery optimize the chances of a successful result $[39,41]$.

After surgery, the foot is protected by a splint. When the wound condition is proper, typically 2 to 4 days after surgery, the foot is placed in a short leg weight-bearing cast or a walker for 6 weeks, and a brace may be used for 4 to 6 additional weeks. Most importantly, the patient is allowed for full weight-bearing from the beginning, with only exception where additional surgeries do not allow it (e.g., correcting tibial osteotomies). After the cast is removed, the rehabilitation program was started, with gradual return to full activities as tolerated. Radiological controls are made 6 weeks, 

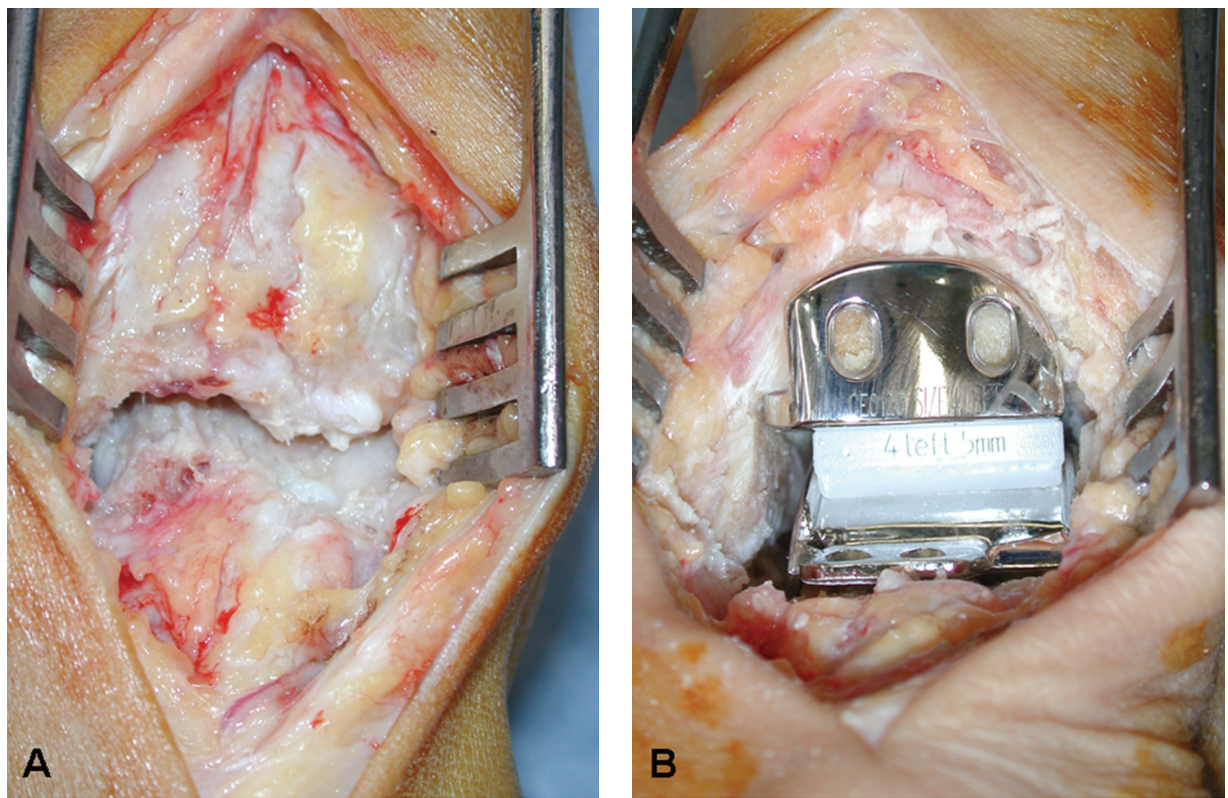

FigURE 1: Intraoperative pictures of (A) exposure of arthritic ankle, and (B) after implantation of prosthesis. 66-year-old female patient after septic arthritis.
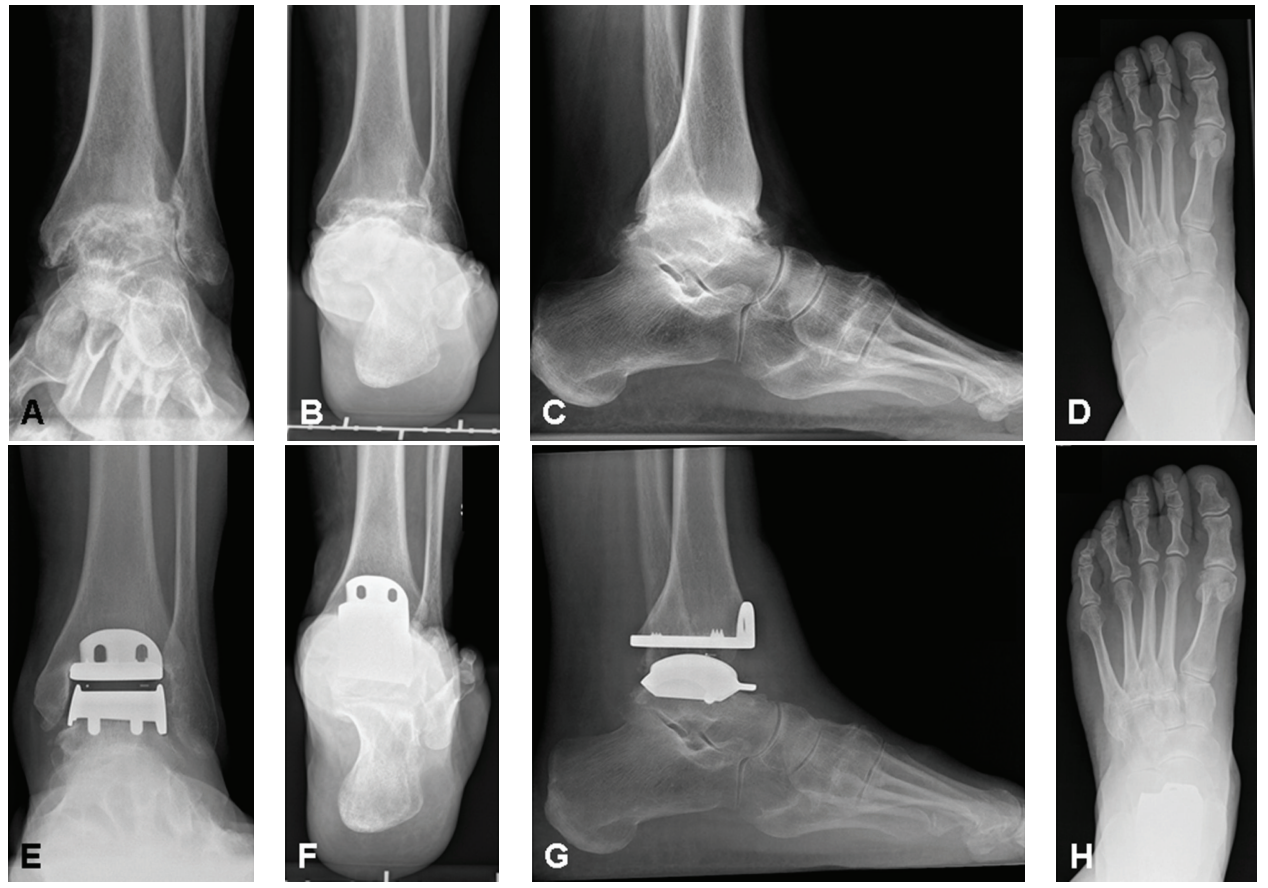

Figure 2: Radiologic evaluation preoperatively (A-D) and after 5 years (E-H): AP view of the ankle (A, E), Saltzman alignment view (B, F), lateral view $(\mathrm{C}, \mathrm{G})$, and AP view of the foot $(\mathrm{D}, \mathrm{H})$. Same patient as in Figure 1.

4 months, and 12 months after surgery and then annually (Figure 2).

\section{Results}

In the orthopaedic literature, there are very few studies that compare implants head to head that are either Level I or Level II, and the superiority of an implant design over another cannot be supported by any available data from Level IV studies [42]. The experiences of several national joint registries have been published previously [43-46]. No statistically significant risk factors (e.g., age, gender, type of prosthesis, underlying etiology) have been identified as influencing survivorship of prosthesis components in 

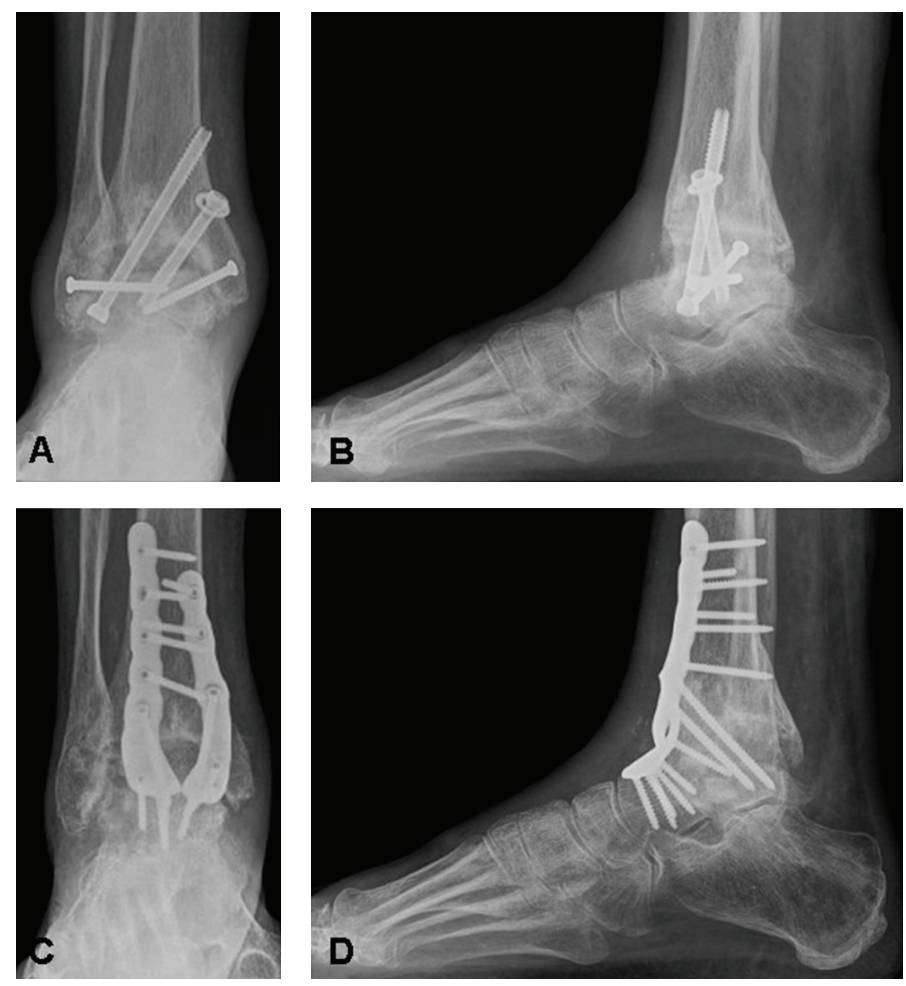

FIGURE 3: 71-year-old male patient, 5 years after attempted fusion of the ankle (A-B). He was never pain-free. His orthopaedic surgeon led him in believe that the ankle was completely fused. One year after revision arthrodesis using a rigid anterior plate fixation, the fusion was healed and the patient was pain-free (C-D).

Norwegian Arthroplasty Register [43], Finnish Arthroplasty Register [46], and New Zealand National Joint Registry [45]. In the Swedish Ankle Arthroplasty Register, lower age at TAR surgery was associated with increased risk of revision whereas preoperative diagnosis or gender did not [44]. Prosthesis misalignment and aseptic loosening have been consistently found to be the most common cause for prosthesis revision [43-46]. A recent systematic review of the literature including 13 Level IV studies with 1105 TARs showed the overall failure rate of approximately $10 \%$ at 5 years with a wide range between $0 \%$ and $32 \%$ [42].

Based on our own registry on 394 ankles (female, 199; male 195; mean age 59.7 [25.3-90.0] years) with a minimal followup of 5 years, our revision free rate at 5 years was $95.1 \%$ and $85.6 \%$ at 10 years. The revision rate was higher in posttraumatic osteoarthritis than in primary or systemic osteoarthritis. There was no difference in outcome between female and male patients. Over 60-year-old patients evidenced, fewer complications than those patients of less than 60 years old, and they had also fewer revisions.

\section{Complications}

Numerous reports describing several techniques for ankle arthrodesis report the fusion rate of $85 \%$ or greater, which may depend on the presence of infection, deformity, avascular necrosis, and nonunion $[12,47]$. However, only in few studies, a CT scan has been used to assess the postoperative osseous healin; therefore, the reported fusion rate of up to $100 \%$ may be overestimated. Since 2008, a total of 38 patients presented in author's outpatient clinic with persistent pain after ankle arthrodesis related to a nonunion (Figure 3), 31 patients $(81.6 \%)$ were thought to have undergone successful ankle fusion by their treating orthopaedic surgeon.

The incidence of nonunion in ankle arthrodesis to a certain extent depends on the surgical technique used [12, 47]. Open procedures involve greater soft-tissue stripping than limited open or arthroscopic techniques. Poor bone quality as typically is the case in elderly patients remains a challenge for achieving primary stability for both external and internal fixation. Newer techniques with rigid plate fixation have shown superior results but may be associated with a higher risk of soft tissue complications or need for hardware removal due to discomfort $[13,48,49]$.

Beside nonunion, mal-union of the fused ankle is another one of the most disabling conditions. The most common mal-union is due to unphysiological plantar flexed position [31]. In addition to consecutively developed metatarsalgia, the longstanding plantar flexed mal-union may be a risk factor for development of degenerative changes in subtalar and/or talonavicular joints. Fusion in dorsiflexion, by contrast, may lead to "back-kneeing" or genu recurvatum. This, in turn, places the patient's center of gravity in front of the weight-bearing axis causing vaulting over the improperly 

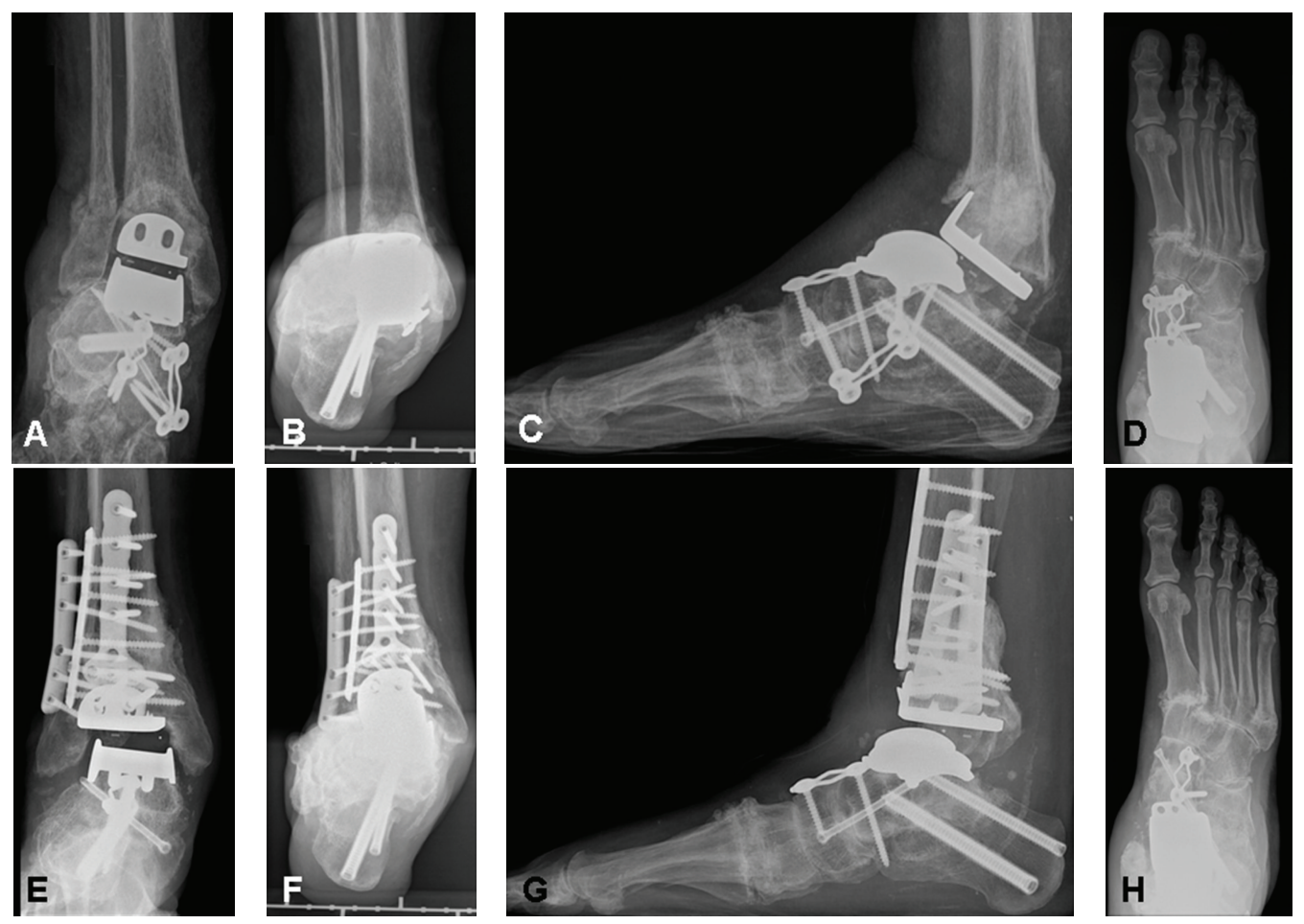

Figure 4: Periprosthetic fracture in a 61-year-old female patient with rheumatoid arthritis after struggling on the stairs. Marked angulation into valgus (A-B) and recurvatum (C), with supination of the foot (D). Uneventful evolution after internal fixation. One year afterwards, the ankle was stable and the patient was able to walk without any pain, though the ankle was still in slight valgus (E-F). Correct situation in lateral view $(\mathrm{G})$ and $\mathrm{AP}$ view $(\mathrm{H})$ of the foot.

positioned foot. Varus or valgus malunion may also present problems but usually only if severe.

In preserving joint motion, TAR offers an excellent alternative to arthrodesis and its sequelae [50-52]. The early complications after TAR include break down of wounds and superficial and deep infection [53, 54]. With current techniques and implants, the risk of primary loosening has dramatically decreased. Nevertheless, in the presence of poor bone quality, a successfully replaced ankle may be susceptible to periprothetic fracture during early remodelling phase (Figure 4).

The main risk of failure after total ankle replacement results from not achieving a balanced ankle joint complex [55]. As a majority part of end-stage osteoarthritic ankles will present with associated problems such as misaligned hindfoot, varus or valgus tilt of talus within the mortise, instability, or soft tissue contractures, the surgeon must be familiar with addressing these associated problems to get a successful replaced ankle $[39,56]$. Surgeon's experience may thus play a superior role for success in TAR [57-60].

The use of TAR in elderly patients still remains controversial in orthopaedic surgery [52]. Kofoed and LundbergJensen [61] have performed a prospective study reporting 100 consecutive cases of patients with osteoarthritis or rheumatoid arthritis with a followup up to 15 years. In all patients, Scandinavian Total Ankle Replacement has been used. All patients were divided into two groups: younger and older than 50 years. The authors found that TAR is a safe and reliable procedure for both, younger and elderly patients with $75.0 \%$ and $80.6 \%$ survivorship at 6 years, respectively [61]. Several other studies have shown a more favourable outcome of TAR in patients with rheumatoid arthritis and elderly low-demand patients with degeneration ankle arthritis [6267]. Spirt et al. [68] have analyzed the cause and frequency of reoperation and failure after 306 primary total ankle arthroplasties using DePuy Agility prosthesis. Age at the time of the primary TAR was the only covariate that had an impact on the hazard of reoperation and failure: each one-year increase in age corresponded with a $1.9 \%$ relative decrease in the hazard of reoperation and 3.5\% decrease in the hazard of failure [68].

The ideal patient for TAR continues to be debated within the orthopaedic foot and ankle surgeons [52]. However, in the most studies, the ideal candidate for TAR has been identified as reasonably mobile, middle aged or older patient, with no obesity or overweight and well aligned and stable hindfoot $[52,62,69-76]$.

\section{Conclusions}

TAR has evolved as a reliable and safe alternative to arthrodesis in the treatment of end-stage ankle osteoarthritis [50, 53, 77]. Reduction in device constraint realized by the contemporary prosthetic designs in comparison with the first generation devices and improved instrumentation has markedly contributed to this higher success. Clinical longevity of TAR 
is dependent upon a correct balance between the intrinsic mobility allowed by the design and the presenting pathology of the patient [55]. This is further influenced by the ability of the surgeon to appropriately balance the soft tissue constraints and correctly align the components [57-60]. Despite improvement in designing appropriate surgical training, experience and technique will ultimately determine the results of total ankle arthroplasty [57-60].

The elderly patient may benefit more by TAR then the alternative ankle arthrodesis. First, postoperative rehabilitation after TAR is easier than that after ankle arthrodesis, allowing for full weight-bearing from the beginning. Immobilization and protection time is usually also markedly shorter for TAR. Thus, loss of articular and muscular function may be less than that after ankle arthrodesis [78-80]. Second, TAR may better restore hindfoot biomechanics, resulting in less gait adoptions and functional impairment [81]. Finally, TAR is in particular promising for elderly patients as the physical demands are, in general, lower. In summary, TAR has yielded to a valuable alternative to ankle arthrodesis and thus can be recommended in elderly patients as a very promising option to regain life quality and function.

\section{References}

[1] D. D. Anderson, S. Chubinskaya, F. Guilak et al., "Posttraumatic osteoarthritis: improved understanding and opportunities for early intervention," Journal of Orthopaedic Research, vol. 29, no. 6, pp. 802-809, 2011.

[2] M. Knupp, V. Valderrabano, and B. Hintermann, "Anatomical and biomechanical aspects of total ankle replacement," Orthopade, vol. 35, no. 5, pp. 489-494, 2006.

[3] M. Müller-Gerbl, "Anatomy and biomechanics of the ankle joint,” Orthopade, vol. 30, no. 1, pp. 3-11, 2001.

[4] M. Glazebrook, T. Daniels, A. Younger et al., "Comparison of health-related quality of life between patients with end-stage ankle and hip arthrosis," Journal of Bone and Joint Surgery Series A, vol. 90, no. 3, pp. 499-505, 2008.

[5] C. L. Saltzman, M. L. Salamon, G. M. Blanchard et al., "Epidemiology of ankle arthritis: report of a consecutive series of 639 patients from a tertiary orthopaedic center," The Iowa Orthopaedic Journal, vol. 25, pp. 44-46, 2005.

[6] V. Valderrabano, M. Horisberger, I. Russell, H. Dougall, and B. Hintermann, "Etiology of ankle osteoarthritis," Clinical Orthopaedics and Related Research, vol. 467, no. 7, pp. 18001806, 2009.

[7] V. Valderrabano, B. Hintermann, M. Horisberger, and S. F. Tak, "Ligamentous posttraumatic ankle osteoarthritis," American Journal of Sports Medicine, vol. 34, no. 4, pp. 612-620, 2006.

[8] A. Barg, A. Elsner, D. Hefti, and B. Hintermann, "Total ankle arthroplasty in patients with hereditary hemochromatosis," Clinical Orthopaedics and Related Research, vol. 469, no. 5, pp. 1427-1435, 2011.

[9] A. Barg, A. Elsner, D. Hefti, and B. Hintermann, "Haemophilic arthropathy of the ankle treated by total ankle replacement: a case series," Haemophilia, vol. 16, no. 4, pp. 647-655, 2010.

[10] A. Barg, M. Knupp, A. L. Kapron, and B. Hintermann, "Total ankle replacement in patients with gouty arthritis," Journal of Bone and Joint Surgery, vol. 93, no. 4, pp. 357-366, 2011.
[11] M. Knupp, A. Barg, L. Bolliger, and B. Hintermann, "Supramalleolar osteotomies for the treatment of overcorrected clubfoot deformity," Journal of Bone and Joint Surgery. In press.

[12] A. Nihal, R. E. Gellman, J. M. Embil, and E. Trepman, "Ankle arthrodesis," Foot and Ankle Surgery, vol. 14, no. 1, pp. 1-10, 2008.

[13] C. Plaass, M. Knupp, A. Barg, and B. Hintermann, "Anterior double plating for rigid fixation of isolated tibiotalar arthrodesis," Foot and Ankle International, vol. 30, no. 7, pp. 631-639, 2009.

[14] J. M. Mazur, E. Schwartz, and S. R. Simon, "Ankle arthrodesis. Long-term follow-up with gait analysis," Journal of Bone and Joint Surgery Series A, vol. 61, no. 7, pp. 964-975, 1979.

[15] G. N. Boobbyer, "The long-term results of ankle arthrodesis," Acta Orthopaedica Scandinavica, vol. 52, no. 1, pp. 107-110, 1981.

[16] S. Fuchs, C. Sandmann, A. Skwara, and C. Chylarecki, "Quality of life 20 years arthrodesis of the ankle," Journal of Bone and Joint Surgery Series B, vol. 85, no. 7, pp. 994-998, 2003.

[17] P. Piriou, P. Culpan, M. Mullins, J. N. Cardon, D. Pozzi, and T. Judet, "Ankle replacement versus arthrodesis: a comparative gait analysis study," Foot and Ankle International, vol. 29, no. 1, pp. 3-9, 2008.

[18] K. M. Schweitzer and S. G. Parekh, "Comparison of gait biomechanics: ankle fusion versus ankle replacement," Seminars in Arthroplasty, vol. 21, no. 4, pp. 223-229, 2010.

[19] W. L. Wu, F. C. Su, Y. M. Cheng, P. J. Huang, Y. L. Chou, and C. K. Chou, "Gait analysis after ankle arthrodesis," Gait and Posture, vol. 11, no. 1, pp. 54-61, 2000.

[20] L. M. Coester, C. L. Saltzman, J. Leupold, and W. Pontarelli, "Long-term results following ankle arthrodesis for posttraumatic arthritis," Journal of Bone and Joint Surgery Series A, vol. 83, no. 2, pp. 219-228, 2001.

[21] C. L. Saltzman, R. A. Mann, J. E. Ahrens et al., "Prospective controlled trial of STAR total ankle replacement versus ankle fusion: initial results," Foot and Ankle International, vol. 30, no. 7, pp. 579-596, 2009.

[22] World Health Organization, "Definition of an older or elderly person," 2012, http://www.who.int/healthinfo/survey/ageingdefnolder/en/index.html.

[23] J. W. Brodsky, F. E. Polo, S. C. Coleman, and N. Bruck, "Changes in gait following the scandinavian total ankle replacement," Journal of Bone and Joint Surgery Series A, vol. 93, no. 20, pp. 1890-1896, 2011.

[24] C. Nüesch, V. Valderrabano, C. Huber, T. V. von, and G. Pagenstert, "Gait patterns of asymmetric ankle osteoarthritis patients," Clinical Biomechanics. In press.

[25] V. Valderrabano, B. M. Nigg, V. von Tscharner, D. J. Stefanyshyn, B. Goepfert, and B. Hintermann, "Gait analysis in ankle osteoarthritis and total ankle replacement," Clinical Biomechanics, vol. 22, no. 8, pp. 894-904, 2007.

[26] V. Valderrabano, B. Hintermann, B. M. Nigg, D. Stefanyshyn, and P. Stergiou, "Kinematic changes after fusion and total replacement of the ankle_-part 2: movement transfer," Foot and Ankle International, vol. 24, no. 12, pp. 888-896, 2003.

[27] V. Valderrabano, B. Hintermann, B. M. Nigg, D. Stefanyshyn, and P. Stergiou, "Kinematic changes after fusion and total replacement of the ankle-part 1: range of motion," Foot and Ankle International, vol. 24, no. 12, pp. 881-887, 2003.

[28] V. Valderrabano, B. Hintermann, B. M. Nigg, D. Stefanyshyn, and P. Stergiou, "Kinematic changes after fusion and total replacement of the ankle-part 3: talar movement," Foot and Ankle International, vol. 24, no. 12, pp. 897-900, 2003. 
[29] B. Hintermann and A. Barg, "The HINTEGRA total ankle arthroplasty," in Operative Techniques in Orthopaedic Surgery, S. W. Wiesel, Ed., pp. 4022-4031, Lippincott Williams \& Wilkins, 2010.

[30] A. Barg, H. B. Henninger, M. Knupp, and B. Hintermann, "Simultaneous bilateral total ankle replacement using a 3component prosthesis: outcome in 26 patients followed for 2 10 years," Acta Orthopaedica, vol. 82, no. 6, pp. 704-710, 2011.

[31] B. Hintermann, A. Barg, M. Knupp, and V. Valderrabano, "Conversion of painful ankle arthrodesis to total ankle arthroplasty," Journal of Bone and Joint Surgery Series A, vol. 91, no. 4, pp. 850-858, 2009.

[32] M. Horisberger, B. Hintermann, and V. Valderrabano, "Alterations of plantar pressure distribution in posttraumatic endstage ankle osteoarthritis," Clinical Biomechanics, vol. 24, no. 3, pp. 303-307, 2009.

[33] C. L. Saltzman and G. Y. El-Khoury, "The hindfoot alignment view," Foot and Ankle International, vol. 16, no. 9, pp. 572-576, 1995.

[34] M. Knupp, G. I. Pagenstert, A. Barg, L. Bolliger, M. E. Easley, and B. Hintermann, "SPECT-CT compared with conventional imaging modalities for the assessment of the varus and valgus malaligned hindfoot," Journal of Orthopaedic Research, vol. 27, no. 11, pp. 1461-1466, 2009.

[35] G. I. Pagenstert, A. Barg, A. G. Leumann et al., "SPECT-CT imaging in degenerative joint disease of the foot and ankle," Journal of Bone and Joint Surgery Series B, vol. 91, no. 9, pp. 1191-1196, 2009.

[36] S. Brunner, M. Knupp, and B. Hintermann, "Total ankle replacement for the valgus unstable osteoarthritic ankle," Techniques in Foot and Ankle Surgery, vol. 9, no. 4, pp. 165174, 2010.

[37] B. S. Kim, W. J. Choi, Y. S. Kim, and J. W. Lee, "Total ankle replacement in moderate to severe varus deformity of the ankle," Journal of Bone and Joint Surgery Series B, vol. 91, no. 9, pp. 1183-1190, 2009.

[38] B. S. Kim and J. W. Lee, "Total ankle replacement for the varus unstable osteoarthritic ankle," Techniques in Foot and Ankle Surgery, vol. 9, no. 4, pp. 157-164, 2010.

[39] M. Knupp, S. A. S. Stufkens, L. Bolliger, S. Brunner, and B. Hintermann, "Total ankle replacement and supramalleolar osteotomies for malaligned osteoarthritic ankles," Techniques in Foot and Ankle Surgery, vol. 9, no. 4, pp. 175-181, 2010.

[40] M. Knupp, L. Bolliger, A. Barg, and B. Hintermann, "Total ankle replacement for varus deformity," Orthopade, vol. 40, no. 11, pp. 964-970, 2011.

[41] M. Knupp, S. A. S. Stufkens, L. Bolliger et al., "Classification and treatment of supramalleolar deformities," Foot and Ankle International, vol. 32, pp. 1023-1031, 2011.

[42] N. Gougoulias, A. Khanna, and N. Maffulli, "How successful are current ankle replacements? A systematic review of the literature," Clinical Orthopaedics and Related Research, vol. 468, no. 1, pp. 199-208, 2010.

[43] B. T. S. Fevang, S. A. Lie, L. I. Havelin, J. G. Brun, A. Skredderstuen, and O. Furnes, "257 ankle arthroplasties performed in Norway between 1994 and 2005," Acta Orthopaedica, vol. 78, no. 5, pp. 575-583, 2007.

[44] A. Henricson, A. Skoog, and A. Carlsson, "The Swedish ankle Arthroplasty Register: an analysis of 531 arthroplasties between 1993 and 2005," Acta Orthopaedica, vol. 78, no. 5, pp. 569-574, 2007.

[45] A. H. Hosman, R. B. Mason, T. Hobbs, and A. G. Rothwell, "A New Zealand national joint registry review of 202 total ankle replacements followed for up to 6 years," Acta Orthopaedica, vol. 78, no. 5, pp. 584-591, 2007.

[46] E. T. Skyttä, H. Koivu, A. Eskelinen, M. Ikävalko, P. Paavolainen, and V. Remes, "Total ankle replacement: a population-based study of 515 cases from the Finnish Arthroplasty Register," Acta Orthopaedica, vol. 81, no. 1, pp. 114-118, 2010.

[47] N. A. Abidi, G. S. Gruen, and S. F. Conti, "Ankle arthrodesis: indications and techniques," The Journal of the American Academy of Orthopaedic Surgeons, vol. 8, no. 3, pp. 200-209, 2000.

[48] A. Mohamedean, H. G. Said, M. El-Sharkawi, W. El-Adly, and G. Z. Said, "Technique and short-term results of ankle arthrodesis using anterior plating," International Orthopaedics, vol. 34, no. 6, pp. 833-837, 2010.

[49] I. S. Tarkin, M. A. Mormino, M. P. Clare, H. Haider, A. K. Walling, and R. W. Sanders, "Anterior plate supplementation increases ankle arthrodesis construct rigidity," Foot and Ankle International, vol. 28, no. 2, pp. 219-223, 2007.

[50] D. E. Bonasia, F. Dettoni, J. E. Femino, P. Phisitkul, M. Germano, and A. Amendola, "Total ankle replacement: why, when and how?" The Iowa Orthopaedic Journal, vol. 30, pp. 119-130, 2010.

[51] M. E. Easley, S. B. Adams Jr., W. C. Hembree, and J. K. DeOrio, "Results of total ankle arthroplasty," Journal of Bone and Joint Surgery Series A, vol. 93, no. 15, pp. 1455-1468, 2011.

[52] A. J. Guyer and E. G. Richardson, "Current concepts review: total ankle arthroplasty," Foot and Ankle International, vol. 29, no. 2, pp. 256-264, 2008.

[53] B. Hintermann and V. Valderrabano, "Total ankle replacement," Foot and Ankle Clinics, vol. 8, no. 2, pp. 375-405, 2003.

[54] V. Valderrabano, G. I. Pagenstert, and B. Hintermann, "Total ankle replacement-three-component prosthesis," Techniques in Foot \& Ankle Surgery, vol. 2, pp. 84-90, 2005.

[55] B. Hintermann, "Total ankle replacement in Switzerland," Orthopade, vol. 40, p. 963, 2011.

[56] A. Barg, T. Suter, L. Zwicky, M. Knupp, and B. Hintermann, "Medial pain syndrome in patients with total ankle replacement," Orthopade, vol. 40, pp. 991-999, 2011.

[57] K. T. Lee, Y. K. Lee, K. W. Young et al., "Perioperative complications of the MOBILITY total ankle system: comparison with the HINTEGRA total ankle system," Journal of Orthopaedic Science, vol. 15, no. 3, pp. 317-322, 2010.

[58] M. S. Myerson and K. Mroczek, "Perioperative complications of total ankle arthroplasty," Foot and Ankle International, vol. 24, no. 1, pp. 17-21, 2003.

[59] C. L. Saltzman, A. Amendola, R. Anderson et al., "Surgeon training and complications in total ankle arthroplasty," Foot and Ankle International, vol. 24, no. 6, pp. 514-518, 2003.

[60] B. G. Schutte and J. W. K. Louwerens, "Short-term results of our first 49 Scandanavian Total Ankle Replacements (STAR)," Foot and Ankle International, vol. 29, no. 2, pp. 124-127, 2008.

[61] H. Kofoed and A. Lundberg-Jensen, "Ankle arthroplasty in patients younger and older than 50 years: a prospective series with long-term follow-up," Foot and Ankle International, vol. 20, no. 8, pp. 501-506, 1999.

[62] M. P. Clare and R. W. Sanders, "Preoperative considerations in ankle replacement surgery," Foot and Ankle Clinics, vol. 7, no. 4, pp. 709-720, 2002.

[63] H. E. Groth and H. F. Fitch, "Salvage procedures for complications of total ankle arthroplasty," Clinical Orthopaedics and Related Research, no. 224, pp. 244-250, 1987.

[64] M. R. McGuire, R. F. Kyle, R. B. Gustilo, and R. F. Premer, "Comparative analysis of ankle arthroplasty vesus ankle 
arthrodesis," Clinical Orthopaedics and Related Research, no. 226, pp. 174-181, 1988.

[65] M. Nagashima, H. Takahashi, S. Kakumoto, Y. Miyamoto, and S. Yoshino, "Total ankle arthroplasty for deformity of the foot in patients with rheumatoid arthritis using the TNK ankle system: clinical results of 21 cases," Modern Rheumatology, vol. 14, no. 1, pp. 48-53, 2004.

[66] F. Shinomiya, M. Okada, Y. Hamada, T. Fujimura, and D. Hamada, "Indications of total ankle arthroplasty for rheumatoid arthritis: evaluation at 5 years or more after the operation," Modern Rheumatology, vol. 13, no. 2, pp. 153-159, 2003.

[67] P. L. R. Wood, L. A. Crawford, R. Suneja, and A. Kenyon, "Total ankle replacement for rheumatoid ankle arthritis," Foot and Ankle Clinics, vol. 12, no. 3, pp. 497-508, 2007.

[68] A. A. Spirt, M. Assal, and S. T. Hansen, "Complications and failure after total ankle arthroplasty," Journal of Bone and Joint Surgery Series A, vol. 86, no. 6, pp. 1172-1178, 2004.

[69] A. Barg, M. Knupp, H. B. Henninger, L. Zwicky, and B. Hintermann, "Total ankle replacement using HINTEGRA-an unconstrained, three-component system: surgical technique and pitfalls," Foot and Ankle Clinics. In press.

[70] L. A. DiDomenico, J. R. Treadwell, and L. Z. Cain, "Total ankle arthroplasty in the rheumatoid patient," Clinics in Podiatric Medicine and Surgery, vol. 27, no. 2, pp. 295-311, 2010.

[71] V. Gibson and D. Prieskorn, "The valgus ankle," Foot and Ankle Clinics, vol. 12, no. 1, pp. 15-27, 2007.

[72] N. E. Gougoulias, A. Khanna, and N. Maffulli, "History and evolution in total ankle arthroplasty," British Medical Bulletin, vol. 89, no. 1, pp. 111-151, 2009.

[73] J. M. Murnaghan, D. S. Warnock, and S. A. Henderson, "Total ankle replacement. Early experiences with STAR prosthesis," Ulster Medical Journal, vol. 74, no. 1, pp. 9-13, 2005.

[74] J. S. Park and K. J. Mroczek, “Total ankle arthroplasty," Bulletin of the NYU Hospital for Joint Diseases, vol. 69, no. 1, pp. 27-35, 2011.

[75] C. L. Saltzman, "Perspective on total ankle replacement," Foot and Ankle Clinics, vol. 5, no. 4, pp. 761-775, 2000.

[76] P. L. R. Wood, T. M. Clough, and R. Smith, "The present state of ankle arthroplasty," Foot and Ankle Surgery, vol. 14, no. 3, pp. 115-119, 2008.

[77] B. Hintermann, Endoprothetik des Sprunggelenks: Historischer Überblick, Aktuelle Therapiekonzepte und Entwicklungen, Springer, Wien, Austria, 2005.

[78] V. Valderrabano, B. Hintermann, V. Von Tscharner, B. Göpfert, W. Dick, and B. Nigg, "Muscle biomechanics in total ankle replacement," Orthopade, vol. 35, no. 5, pp. 513-520, 2006.

[79] V. Valderrabano, B. M. Nigg, V. Von Tscharner, C. B. Frank, and B. Hintermann, "Total ankle replacement in ankle osteoarthritis: an analysis of muscle rehabilitation," Foot and Ankle International, vol. 28, no. 2, pp. 281-291, 2007.

[80] V. Valderrabano, V. von Tscharner, B. M. Nigg, B. Goepfert, C. B. Frank, and B. Hintermann, "Lower leg muscle atrophy in ankle osteoarthritis and its rehabilitation after implantation of a total ankle arthroplasty," Fuss und Sprunggelenk, vol. 5, no. 1, pp. 33-43, 2007.

[81] A. Barg and B. Hintermann, "Implantate und biomechanik des oberen sprunggelenks," in AE-Manual der Endoprothetik: Sprunggelenk und Fuss, W. Neumann, Ed., pp. 29-45, Springer, London, UK, 2012. 


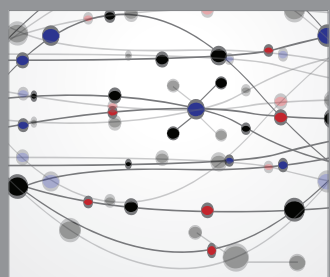

The Scientific World Journal
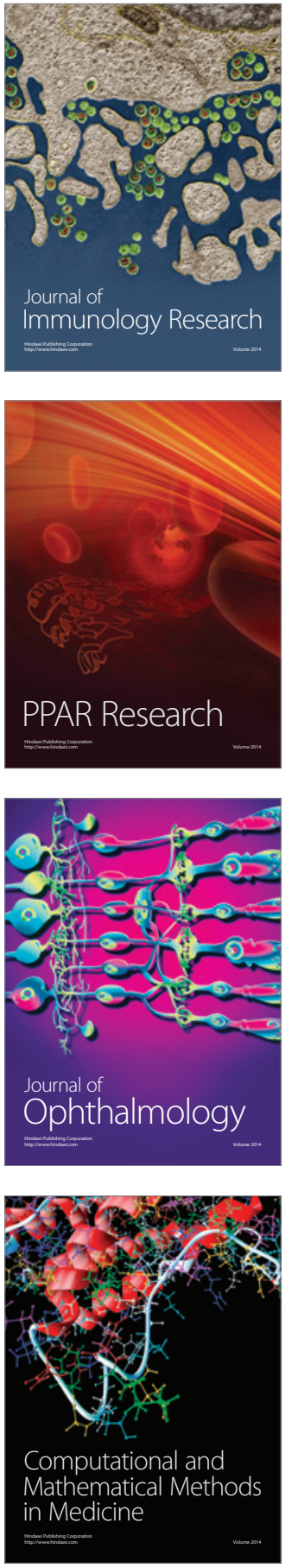

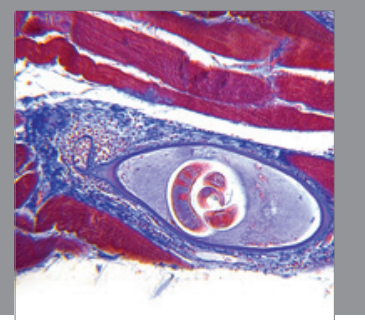

Gastroenterology

Research and Practice
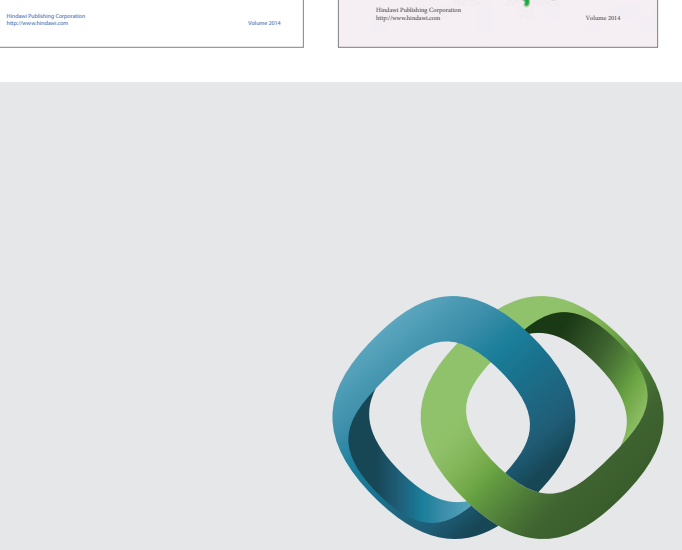

\section{Hindawi}

Submit your manuscripts at

http://www.hindawi.com
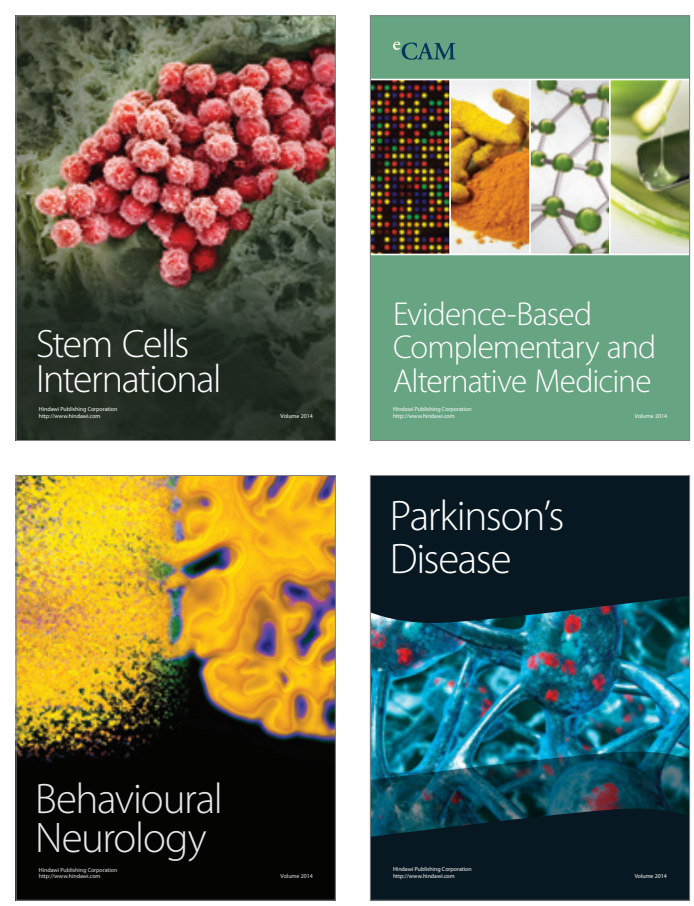

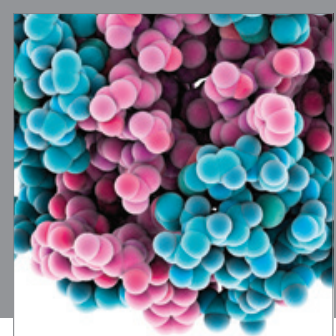

Journal of
Diabetes Research

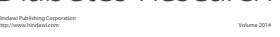

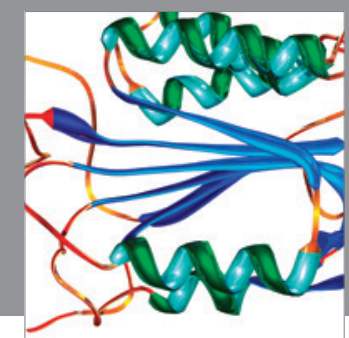

Disease Markers
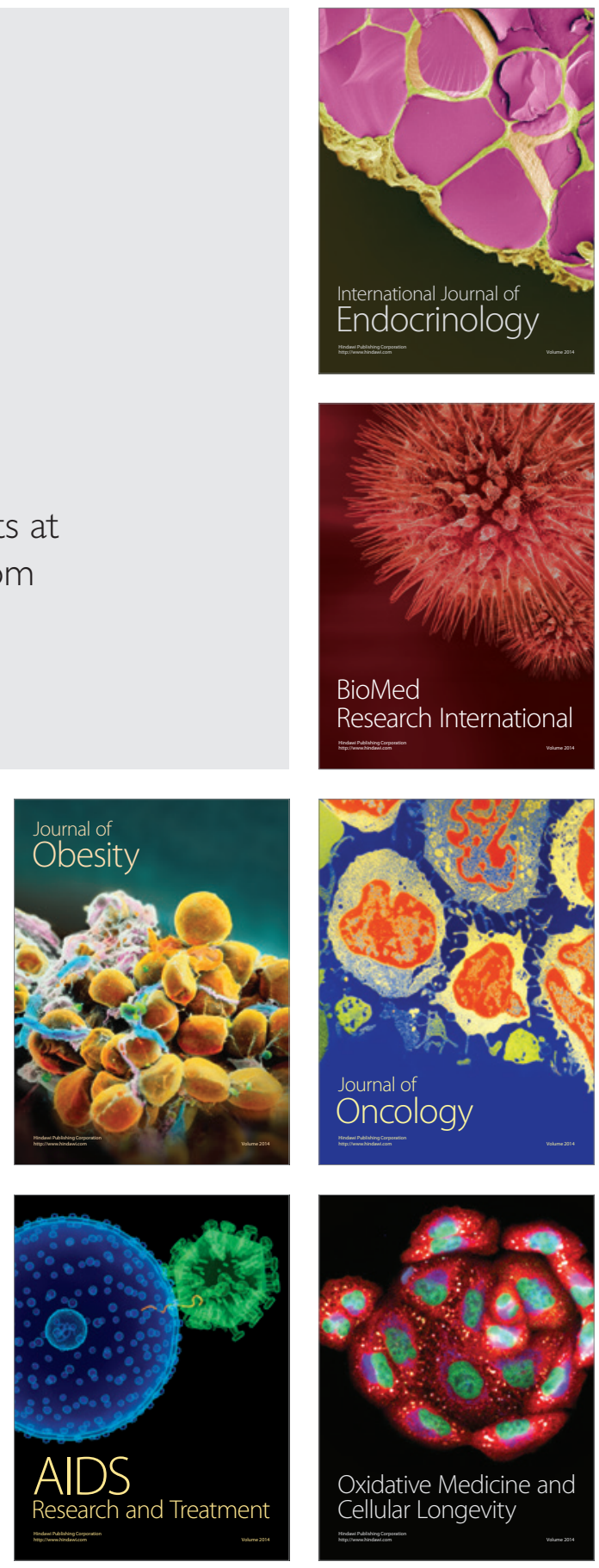